\title{
PERHITUNGAN MATEMATIKA DASAR BERBASIS MULTIMEDIA MENGGUNAKAN METODE JARIMATIKA
}

\author{
Novitasari Ballo ${ }^{1}$ \\ Teknik Informatika Strata Satu STIKOM Uyelindo Kupang \\ Email: novitasaribalo@gmail.com ${ }^{1}$ \\ Menhya Snae ${ }^{2}$ \\ Teknik Informatika Strata Satu STIKOM Uyelindo Kupang \\ Email: Menhyasnae@gmail.com ${ }^{2}$
}

\begin{abstract}
Progress in science and engineering bring about the changes in human life in almost all aspects of life. Education the prevailing current started from the level of education the ground level. One of education the ground level thet develops is primary school (SD). In matters of basic mathematical calculation. Math is one of the lesson the important primary school. Currently has been developing all kinds of methods to count. In essence all those methods is good, all the entitled to studies techniques and children primary school rich in a technique. One method that have evolved to math especially in count is teaching jarimatika method. A jarimatika method is one way to count by using the tools the fingers. With the jarimatika methods students of trained for memorization calculation basic mathematical. The use of a method of jarimatika in a calculation on the mathematics can ease primary school student in learning a summation, the reduction of, multiplication, and division. This needs to the knowing jarimatika method made in the form of multimedia namely interactive multimedia basic mathematical uses the jarimatika method. Interactive multimedia was created using Macromedia Flash 8. The Interactive multimedia made will be applied on primary schools Inpres Oebufu. The Interactive multimedia is made to ease students in learn math and ease teaching and creating a learning more interesting.
\end{abstract}

Keywords: Mathematics, a Method of Jarimatika, Primary School, Multimedia, Education

\section{PENDAHULUAN}

Kemajuan ilmu pengetahuan dan teknologi membawa perubahan dalam kehidupan manusia di hampir semua aspek kehidupan. Pendidikan yang berlaku saat ini dimulai dari jenjang pendidikan tingkat dasar. Salah satu pendidikan tingkat dasar yang berkembang adalah Sekolah Dasar (SD) khususnya dalam bidang perhitungan matematika dasar. Matematika adalah salah satu pelajaran yang penting di sekolah dasar.

Sejalan dengan semakin meningkatnya kegiatan pendidikan di kota Kupang, khususnya dalam bidang matematika pada tingkat sekolah dasar harus dikembangkan dalam metode pembelajaran yang lebih menarik dan menunjang para anak didik untuk tertarik belajar Matematika. Yang masih menjadi masalah adalah bahwa para anak didik kurang tertarik untuk belajar matematika karena memiliki banyak angka yang harus dihitung dan proses pengerjaannyapun cukup rumit untuk dipahami pada tingkat dasar, sehingga menyebabkan rendahnya tingkat hasil belajar siswa dan guru kesulitan membuat pembelajaran yang menarik bagi siswa sekolah dasar. Pada Sekolah Dasar Inpres Oebufu Kupang penulis mengambil beberapa sampel siswa kelas 3-6 yang memiliki kesulitan dalam mempelajari perkalian dan pembagian tetapi mereka mampu memahami penjumlahan dan pengurangan.

Menurut Prasetyono [1] saat ini telah berkembang macam-macam metode untuk berhitung. Pada intinya semua metode adalah baik, semua anak berhak untuk mempelajari teknik-teknik yang ada sehingga anak sekolah dasar kaya akan suatu teknik. Salah satu metode yang telah berkembang untuk pelajaran Matematika khususnya dalam berhitung adalah pengajaran metode jarimatika. Metode jarimatika adalah salah satu cara berhitung dengan menggunakan alat bantu jari tangan. Dengan metode jarimatika ini siswa dilatih 
untuk menghafal perkalian dasar. Metode hitung menggunakan jari tangan dapat membuat pembelajaran semakin menyenangkan. Siswa dapat menggunakan jari tangannya untuk menyelesaikan permasalahan berhitung berdasarkan aturan formasi tangan dengan penyelesaian jarimatika. Media jarimatika ini selain fleksibel juga tidak memberatkan memori otak anak dalam proses berhitung dan menunjukkan tingkat keakuratan yang tinggi.

Palupi [2] dalam penelitiaannya yang berjudul Penggunaan Media Jarimatika Untuk Meningkatkan Hasil Belajar Matematika Materi Perkalian Pada Siswa Kelas IV SD Negeri Combongan III Sukoharjo Tahun Ajaran 2011/2012 mengemukakan pembelajaran matematika dengan penerapan teknik jarimatika dapat meningkatkan kemampuan berhitung siswa, yang meliputi ketepatan siswa dalam melakukan perhitungan sebelum dilakukan tindakan belajar menggunakan metode jarimatika. Pembelajaran melalui penerapan media jarimatika dapat meningkatkan hasil belajar mata pelajaran matematika materi perkalian pada siswa kelas IV SD Negeri Combongan III Sukoharjo

Berdasarkan uraian latar belakang maka yang menjadi permasalahan dalam penelitian ini adalah kurang tertariknya anak sekolah dasar Inpres Oebufu dalam mempelajari matematika. Maka yang menjadi rumusan masalah dalam penelitian ini adalah bagaimana membuat perhitungan matematika dasar berbasis multimedia menggunakan metode jarimatika.

Tujuan yang hendak dicapai dari penelitian ini adalah membuat sebuah aplikasi perhitungan matematika dasar berbasis multimedia menggunakan metode jarimatika.

Adapun manfaat yang akan diperoleh dari penelitian ini adalah sebagai berikut:

1. Mempermudah perhitungan matematika dasar pada murid kelas 3-6 Sekolah Dasar Inpres Oebufu Kupang.

2. Mempermudah guru dalam pemberian materi pembelajaran.

3. Aplikasi ini bisa digunakan di sekolah dan juga di rumah.
Vol. 2, No. 2, Desember, 2016

Agar tidak menyimpang dari permasalahan yang dibahas maka penulis memberikan batasan masalah pada pembuatan aplikasi multimedia pembelajaran matematika dasar ini, yaitu:

1. Aplikasi multimedia yang dibuat hanya ditujukan pada anak Sekolah Dasar Inpres Oebufu Kupang dari kelas 3-6.

2. Perhitungan yang disajikan berupa perhitungan matematika dasar yaitu penjumlahan, pengurangan, perkalian, dan pembagian.

3. Aplikasi multimedia ini menggunakan bahasa pemrograman Macromedia Flash 8.

4. Penerapan aplikasi ini hanya di terapkan pada anak Sekolah Dasar Inpres Oebufu Kupang dari kelas 3-6

\section{METODE PENELITIAN}

Pada penelitian ini terdapat beberapa tahap yang dilakukan yaitu studi literatur dengan mempelajari referensi-referensi yang terkait dengan penelitian ini, pengumpulan data, analisis sistem berupa analisis masalah, pemecahan dan kebutuhan, kemudian langkah selanjutnya adalah perancangan sistem yang secara keseluruhan baik menggunakan use case, maupun setelah itu pengujian sistem apakah berjalan sesuai dengan tujuan penelitian. Apabila sistem menunjukkan hasil yang valid maka sistem siap untuk diimplementasikan sistem, setelah itu pengujian sistem apakah berjalan sesuai dengan tujuan penelitian. Apabila sistem menunjukkan hasil yang valid maka sistem siap untuk diimplementasikan.

\section{Bahan Penelitian}

Bahan penelitian ini terdiri atas wawancara, studi pustaka dan observasi untuk membuat aplikasi multimedia interaktif ini

\section{Peralatan Penelitian}

Peralatan yang digunakan pada penelitian ini dapat dibagi menjadi dua yaitu:

\section{a. Antarmuka perangkat keras}

Perangkat keras yang digunakan untuk menjalankan perangkat lunak adalah sebagai berikut: 
1. Perangkat komputer dengan spesifikasi processor $1,8 \mathrm{GHz}$

2. Harddisk sebagai tempat penyimpanan minimal $40 \mathrm{~GB}$

3. Memory minimal $512 \mathrm{MB}$

b. Antarmuka perangkat lunak

Perangkat lunak yang dibutuhkan untuk mengoperasikan perangkat lunak adalah sebagai berikut:

1) Sistem operasi Windows 7 Ultimate

2) Macromedia Flash 8

3) Microsoft Office 2007

\section{HASIL DAN PEMBAHASAN}

\section{Prosedur Penelitian}

Analisis data menjelaskan cara menganalisis atau teknik mengolah data yang digunakan untuk menarik simpulan dari hasil kajian dari topik yang diteliti dan dapat digambarkan kedalam diagram alir. Adapun prosedur analisis data pada penelitian ini memiliki tahapan yang dimulai dengan studi literatur dan observasi, kemudian identifikasi masalah, tahapan analisis kebutuhan sistem, perancangan perangkat lunak, implementasi dan kemudian diakhiri dengan pengujian perangkat lunak yang dibangun sistem. Tahapan-tahapan tersebut digambarkan pada diagram alir berikut ini:

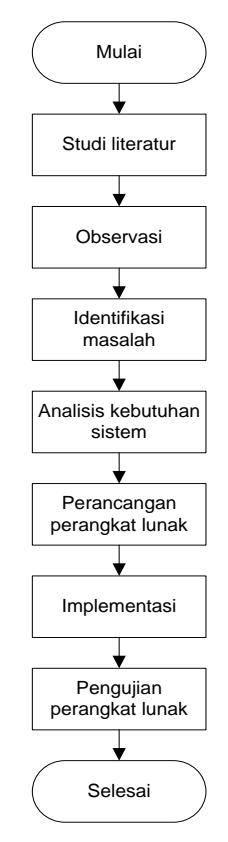

Gambar 1. Prosedur analisis data

\section{Use Case Diagram}

Use case ini memperlihatkan pada pengguna untuk menampilkan informasi perhitungan matematikan dasar berbasis multimedia menggunakan metode jarimatika. Use case dapat dilihat pada Gambar 2 berikut:

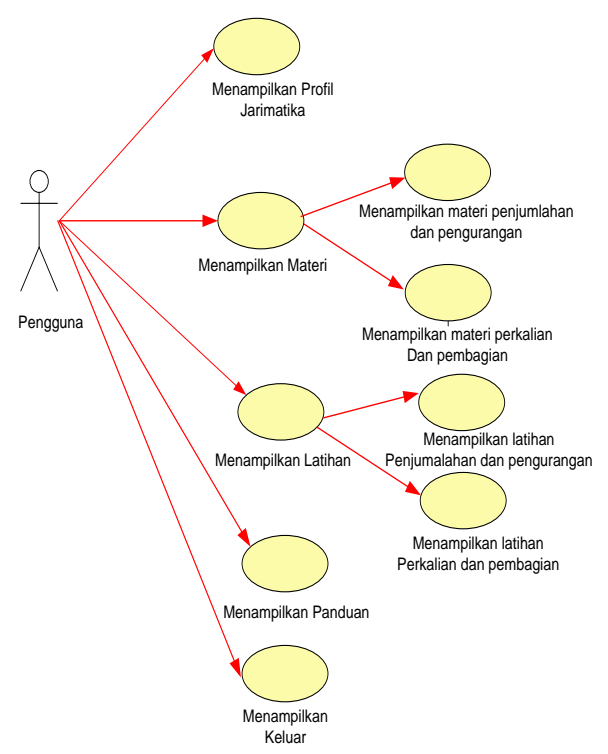

Gambar 2. Use case diagram

\section{Sequence diagram}

Sequence diagram adalah suatu diagram yang menggambarkan interaksi antar obyek dan mengindikasikan komunikasi diantara obyek-obyek tersebut. Diagram ini juga menunjukkan serangkaian pesan yang dipertukarkan oleh obyek-obyek yang melakukan suatu tugas atau aksi tertentu. Interaksi tersebut berupa pesan yang digambarkan terhadap waktu. Sequence diagram terdiri dari dimensi horizontal (objekobjek) dan dimensi vertical (waktu). Membuat diagram sequence juga dibutuhkan untuk melihat skenario yang ada pada use case. Banyaknya diagram sequence yang harus digambar adalah minimal sebanyak pendefinisian use case yang memiliki proses sendiri atau yang penting semua use case yang telah didefinisikan interaksi jalannya pesan sudah dicakup pada diagram sequence sehingga semakin banyak use case yang di definisikan maka diagram sequence yang harus dibuat harus semakin banyak. Perancangan sequence 
ISSN 2477-0043

e-ISSN 2460-7908

diagram dapat dilihat pada gambar-gambar berikut:

1) Sequence diagram profil jarimatika

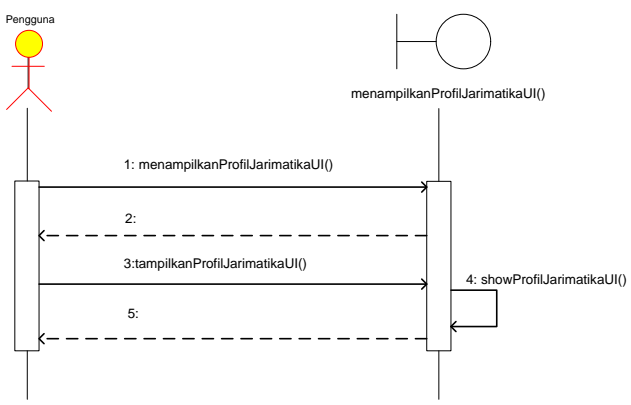

Gambar 3. Sequence diagram profil jarimatika

2) Sequence diagram materi

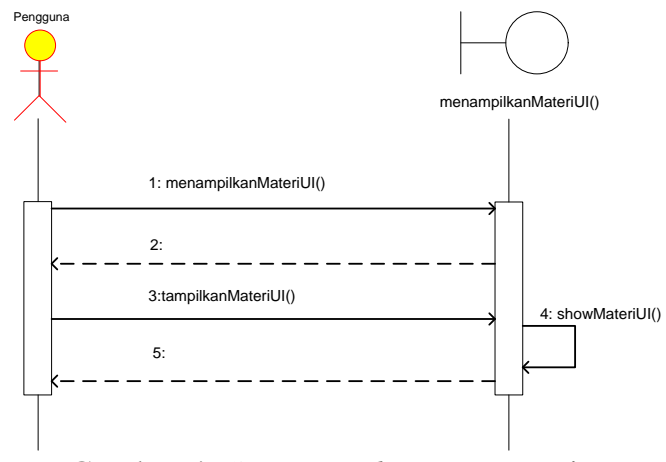

Gambar 4. Sequence diagram materi

3) Sequence diagram latihan
Jurnal Teknologi Terpadu Vol. 2, No. 2, Desember, 2016

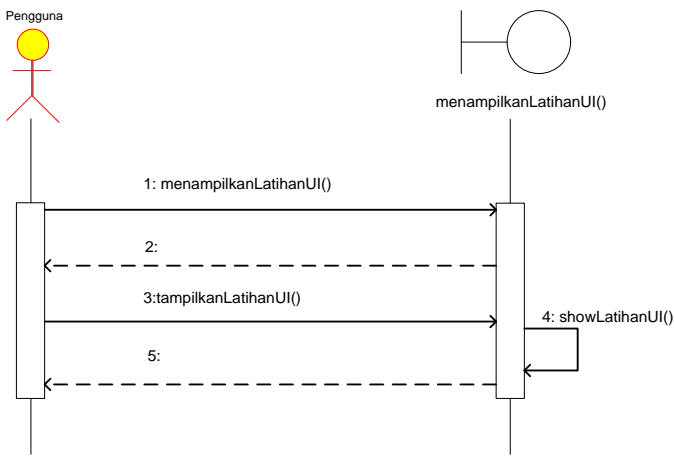

Gambar 5. Sequence diagram latihan

4) Sequence diagram panduan

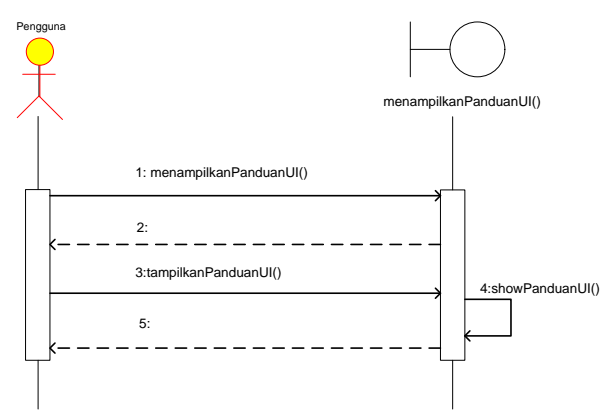

Gambar 6. Sequence diagram panduan

5) Sequence diagram keluar

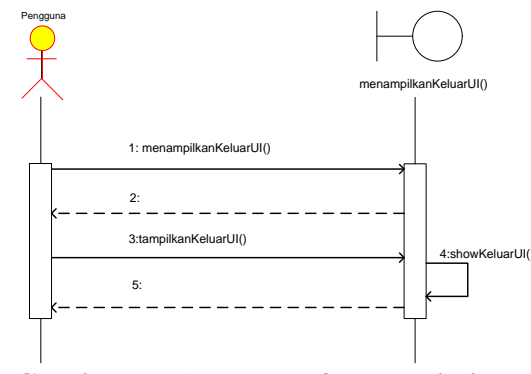

Gambar 7. Sequence diagram keluar

\section{Arsitektur Layar Sistem}

Perancangan arsitektur komputer berfungsi mendeskripsikan kategori sistem sebagai penghubung antar komponen dan user interface. Perancangan arsitektur yang digunakan adalah arsitektur layer (layer architecture) dimana terdapat pemisahan tanggung jawab dari setiap layar. Perancangan arsitektur layar dapat dilihat pada Gambar 3 berikut: 


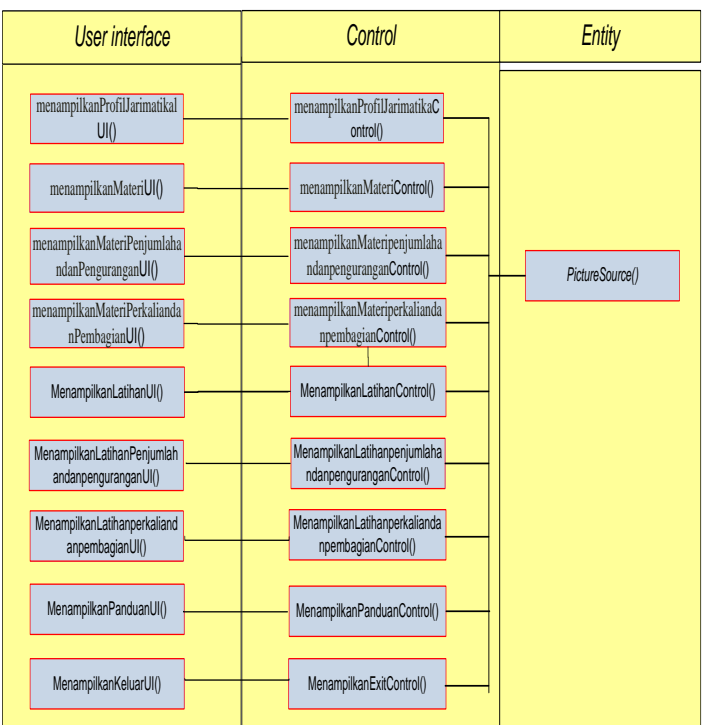

Gambar 3. Arsitektur Layar PERMADA M3 Jarimatika

\section{Class diagram}

Class diagram merupakan suatu diagram yang memperlihatkan atau menampilkan struktur dari sebuah sistem, sistem tersebut akan menampilkan sistem kelas, atribut dan hubungan antar kelas ketika suatu sistem telah selesai membuat diagram. Class diagram adalah diagram yang menggambarkan struktur sistem dari segi pendefinisian kelas-kelas yang akan dibuat untuk membangun sistem. Kelas memiliki tiga bagian utama yaitu atribute, operation, dan name. Kelas-kelas yang ada pada struktur sistem harus dapat melakukan fungsifungsi sesuai dengan kebutuhan sistem. kelas dinyatakan dalam kotak yang terbagi menjadi beberpa kompartemen. Kompartemen pertama berisi nama kelas, berikutnya atribut dan terakhir operasi. Perancangan class diagram PERMADA M3 Jarimatika selengkapnya dapat dilihat pada Gambar 8 berikut:

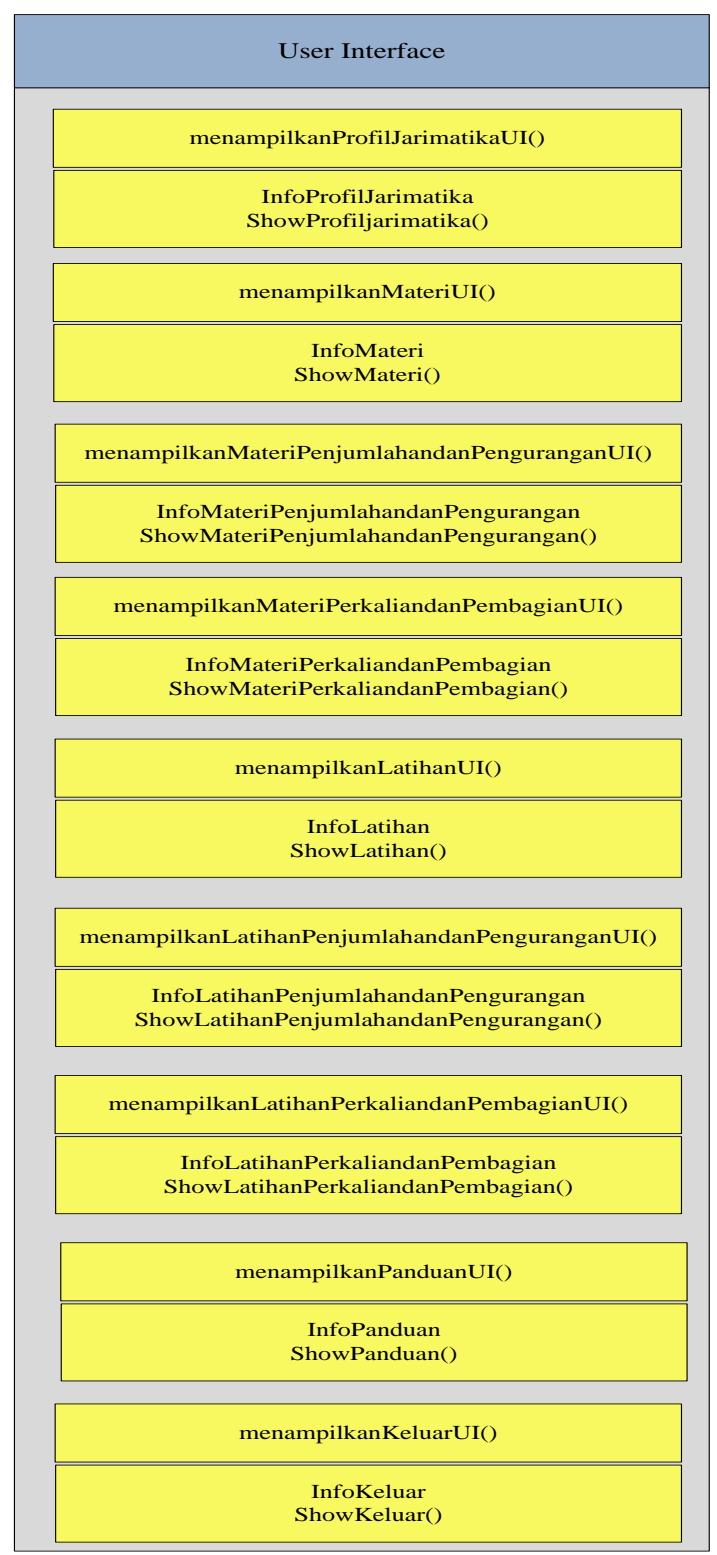

Gambar 8. Class diagram PERMADA M3 Jarimatika

\section{Perancangan Antarmuka}

\section{a. Antarmuka Menu utama}

Antarmuka mеnu awal merupakan proses awal dimulainya pengguna menggunakan sistem untuk menjalankan aplikasi. Gambar di bawah adalah fungsi-fungsi menu yaitu tombol sejarah jarimatika, materi, latihan, panduan, dan keluar. 


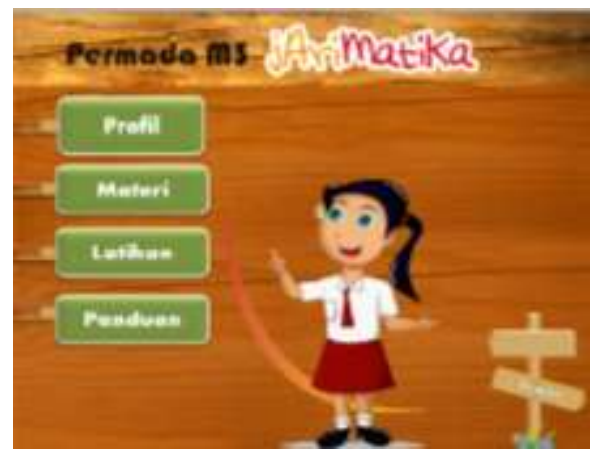

Gambar 9. Antarmuka menu utama

\section{b. Antarmuka Profil Jarimatika}

Antarmuka Profil jarimatika merupakan antarmuka yang menampilkan sejarah ditemukan metode jarimatika dan dikenalkan oleh siapa serta pengertian metode jarimatika. Antarmuka dapat dilihat pada Gambar 10 berikut.

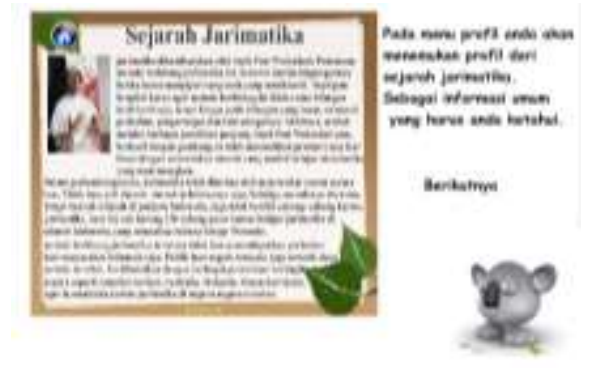

$\overline{\text { Gambar 10. Antarmuka sejarah jarimatika }}$

\section{c. Antarmuka Materi}

Antarmuka materi merupakan antarmuka yang menampilkan materi matematika dasar menggunakan metode jarimatika. Materi yang di sajikan yaitu materi penjumlahan dan pengurangan serta materi perkalian dan pembagian. Antarmuka dapat dilihat pada Gambar 11 berikut.

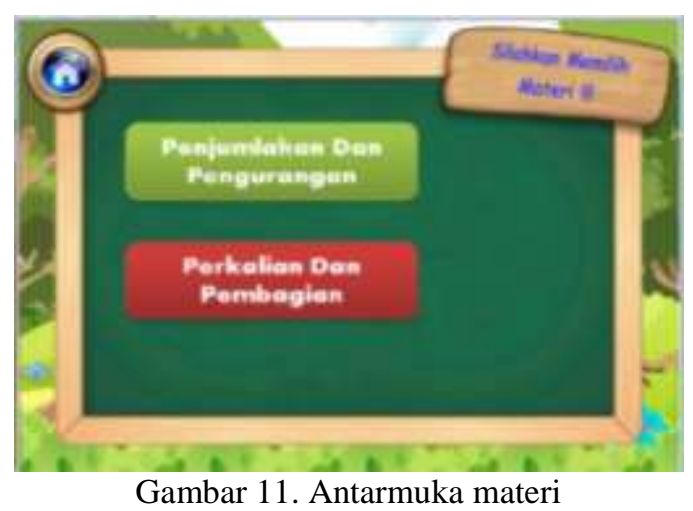

d. Antarmuka latihan
Vol. 2, No. 2, Desember, 2016

Antarmuka latihan merupakan antarmuka yang menampilkan latihan matematika dasar menggunakan metode jarimatika. Latihan yang di sajikan yaitu latihan penjumlahan dan pengurangan serta latihan perkalian dan pembagian. Antarmuka dapat dilihat pada Gambar 12 berikut.

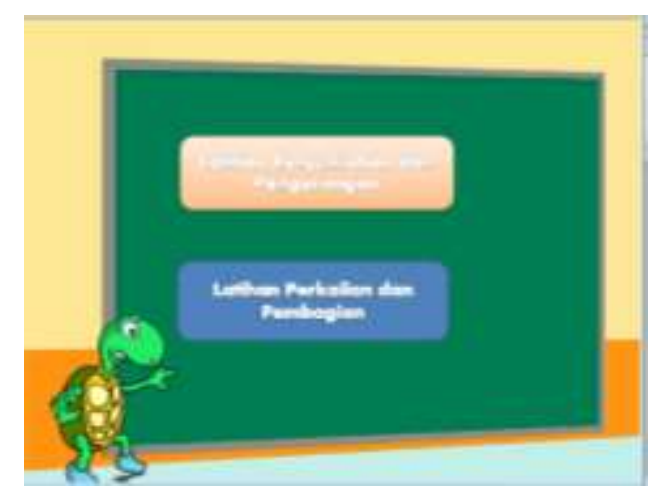

Gambar 12. Antarmuka latihan

\section{e. Antarmuka panduan}

Antarmuka panduan merupakan antarmuka yang menampilkan informasi tentang langkah-langkah untuk menggunakan dan menjalankan aplikasi PERMADA M3 Jarimatika. Antarmuka dapat dilihat pada Gambar 13 berikut.

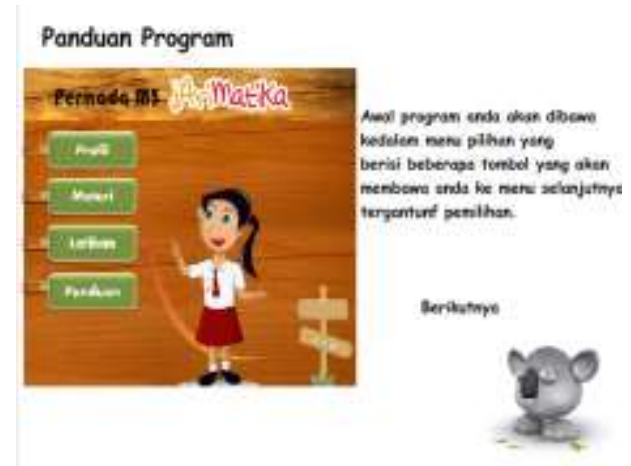

Gambar 13. Antarmuka panduan

f. Antarmuka keluar

Antaramuka keluar merupakan antarmuka yang menampilkan pilihan untuk keluar dari aplikasi PERMADA M3 Jarimatika. Antarmuka dapat dilihat pada Gambar 14 berikut. 


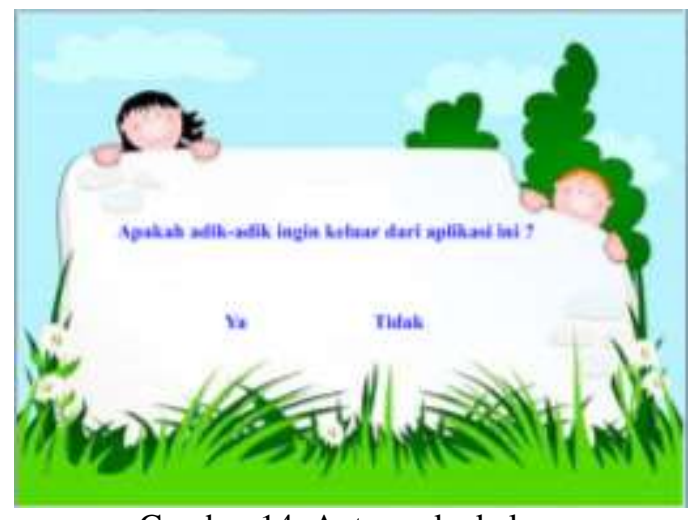

Gambar 14. Antarmuka keluar

\section{SIMPULAN DAN SARAN}

\section{Simpulan}

Kesimpulan dari penulisan skripsi yaitu:

1. Aplikasi Perhitungan Matematika Dasar Berbasis Multimedia Menggunakan Metode Jarimatika (PERMADA M3 Jarimatika) merupakan suatu aplikasi yang dibuat menggunakan Macromedia Flash 8 yang dapat membantu anak Sekolah Dasar Inpres Oebufu kelas 3-6 agar lebih mudah dalam belajar matematika dasar seperti penjumlahan, pengurangan, perkalian, dan pembagian dengan menggunakan jari tangan.

2. Dengan adanya aplikasi PERMADA M3 Jarimatika ini anak Sekolah Dasar Inpres Oebufu mengenal sarana teknologi pembelajaran berbasis multimedia yang dibuat menggunakan Macromedia Flash 8.

\section{Saran}

Pengembangan aplikasi ini masih jauh dari kata sempurna, oleh sebab itu penulis mengharapkan pengembangan aplikasi yang lebih baik dalam penelitian-penelitian selanjutnya. Penerapan aplikasi PERMADA M3 Jarimatika ini hanya memberikan materi untuk matematika dasar sampai bilangan puluhan dan tidak semua bilangan dapat dihitung karena kelemahan dari metode jarimatika yaitu tidak semua bilangan dapat dihitung menggunakan jari tangan. Melihat hal itu maka penulis menyarankan ada pertambahan bilangan ratusan hingga ribuan menggunakan metode jarimatika.

\section{REFERENSI}

[1] Prasetyono. 2008.Teori jarimatika + pengembangannya. Cetakan ke-1. Jakarta (ID): Penerbit: Elex Media Komputindo. Jakarta.

[2] Palupi. 2012. Media Jarimatika Untuk Meningkatkan Hasil Belajar Matematika Materi Perkalian Pada SiswaKelas IV SD Negeri Combongan III Sukoharjo.Sripsi.Pendididikan Guru Sekolah Dasar. Universitas Muhammadiyah. Surakarta. 